\title{
In vitro apoptotic induction of human glioblastoma cells by Fas ligand plus etoposide and in vivo antitumour activity of combined drugs in xenografted nude rats
}

\author{
STÉPHANIE GIRAUD*, BARBARA BESSETTE*, CAROLINE BODA, FABRICE LALLOUÉ, \\ DANIEL PETIT, MURIEL MATHONNET and MARIE-ODILE JAUBERTEAU
}

Laboratory of Immunology, EA 3842, Homéostasie Cellulaire et Pathologies, University Hospital, 87042 Limoges, France

Received July 10, 2006; Accepted September 4, 2006

\begin{abstract}
Human glioblastomas that express Fas/CD95 receptor are highly resistant to conventional brain tumour therapies. The aim of this study is to evaluate anti-tumour properties of a combination of Fas ligand (FasL) plus etoposide with or without dexamethasone on intracerebral experimental glioblastomas. The human Fas-expressing glioblastoma cell line, U-87 MG, was firstly studied in vitro for apoptosis and proliferation assays in the presence of FasL and etoposide, separately or associated, in order to detect a supra-additive effect on FasL or etoposide-induced apoptosis. The tumourigenicity of the U-87 MG cell line and therapeutic effects of FasL-etoposide alone or combined with dexamethasone were next studied on U-87 MG cells xenografted to nude-rat brain and tumour size was hence examined by histological and immunohistochemical stainings. We demonstrated in vitro that the combination of both molecules strongly inhibited the proliferation rate and increased the sensitivity of glioblastoma cells to Fas or etoposide-mediated apoptosis. Moreover, analysis of rat brains was performed 30 days after xenograft
\end{abstract}

Correspondence to: Dr M.O. Jauberteau, Laboratory of Immunology, University Hospital, 2 Martin Luther King avenue, 87042 Limoges, France

E-mail: m-o.jauberteau-marchan@unilim.fr

${ }^{*}$ Contributed equally

Abbreviations: $\mathrm{Ab}$, antibody; BrdU, bromodeoxyuridine; CNS, central nervous system; CSF, cerebrospinal fluid; DISC, deathinducing signalling complex; ELISA, enzyme-linked immunosorbent assay; FasL, Fas ligand; FCS, fetal calf serum; FITC, fluorescein isothiocyanate; GFAP, glial fibrillary protein; HES, hemateineosin-safran; HLA, human leukocyte antigen; Ig, immunoglobulin; $\mathrm{mAb}$, monoclonal antibody; NF, neurofilament; PBS, phosphatebuffer saline; SSC, saline sodium citrate; TNF, tumour necrosis factor; TUNEL, terminal transferase (TdT)-mediated dUTP nick-end labeling

Key words: glioblastoma, Fas ligand, etoposide, dexamethasone, xenografts of glioblastoma cells. These data show that the combination of FasL and etoposide could reduce significantly the tumour size and that the addition of dexamethasone enhanced the inhibiting effect of FasL and etoposide on tumour growth in vivo.

\section{Introduction}

Glioblastomas are the most frequent primary brain tumours in adults. The poor prognosis of patients suffering from these tumours is related to the absence of effective therapies, which could be explained by the intrinsic resistance of glioma cells to apoptosis induced by many chemotherapeutic agents $(1,2)$.

Fas (CD95) is a transmembrane glycoprotein belonging to the tumour necrosis factor (TNF) receptor superfamily. The interaction of Fas with Fas ligand (FasL) results in the recruitment of several adapter molecules to form the deathinducing signaling complex (DISC) (3), leading to apoptotic signal induction through caspase pathways (4). Fas receptor is expressed on activated T and B cells and on a variety of other normal and neoplastic cell types. The apoptotic effect of Fas/FasL pathway depends on the cell type; although it was implicated in some tumour regression in vivo $(2,5)$, it was ineffective in others. However, Fas activation contributes rather to cell proliferation than to apoptosis as described in $\mathrm{T}$ and B-cell lymphoma (6) and glioblastoma (7).

Etoposide, an anti-tumour agent currently used for the treatment of human cancers $(8,9)$, is a topoisomerase II inhibitor that impairs DNA synthesis progression $(10,11)$. In addition, etoposide sensitizes tumour cells to apoptosis by both dependent and independent Fas-signalling pathways. Indeed, its effects on Fas-mediated apoptosis were described in human prostate cancer (12), occurring via Fas receptor activation (13) or independently of Fas ligation by direct processing and activation of caspase-8 (14-16).

High-dose etoposide injected intravenously could penetrate the brain tumour with an efficacious concentration (17). However toxic adverse effects are frequently reported (18). Central nervous system-directed treatment using intraventricular drug injection is one approach to overcoming the blood-brain barrier protective effect against anticancer chemotherapy. Indeed, etoposide had been tested as intraventricular therapy in children with disseminated malignant brain tumours and showed neither discomfort nor long-term 
toxicity but is still under evaluation (19). Therefore, pharmacokinetics studies of the commonly intra-ventriculary applied anticancer agents in humans have demonstrated that, using low drug doses, very high concentrations can be achieved in the cerebrospinal fluid (CSF), but not in the brain tissue. Direct intra-cerebral administration of anticancer drugs by a stereotaxic intra-tumoural injection could be an alternative for the treatment of solid brain tumours such as gliomas. In addition, the combination of two anticancer agents could be a good approach for avoiding chemotherapy resistance. Therefore, we investigated whether FasL and etoposide induced pro-apoptotic and anti-proliferative responses in the human U-87 MG glioblastoma cell line. The cytotoxic effect of molecules was first determined in vitro and the anti-tumour effect of both molecules was evaluated in vivo, after xenografts of U-87 MG cells in nude rat brains, by continuous intra-tumoural drug administration for 14 days after the graft. In addition, dexamethasone was also tested in combination with etoposide and FasL to evaluate the anti-tumour properties of this association. Indeed, while dexamethasone is commonly used as an anti-oedematous drug on glioblastoma patients, it was previously shown as having a slight anti-tumour effect on U-87 MG xenografted cells in nude mice (20). The antitumour effect of these molecules was then evaluated by histological analysis, performed 30 days after the xenograft.

\section{Materials and methods}

Cell line culture. Human glioblastoma cells U-87 MG (ATCC, Manassas, VA) were cultured in MEM with Earl's salts (Gibco BRL, Cergy Pontoise, France) supplemented with $10 \%$ decomplemented fetal calf serum (FCS, Gibco BRL), $1.5 \mathrm{~g} / 1$ sodium bicarbonate, non-essential amino acids, sodium pyruvate $(1 \mathrm{mM})$, penicillin $(50 \mathrm{U} / \mathrm{ml})$, streptomycin $(50 \mu \mathrm{g} / \mathrm{ml})$, L-glutamine $(2 \mathrm{mM})$ and fungizone $(0.1 \%)$ (Gibco BRL). Cells were grown in a flask (Sarstedt, Orsay, France) at $37^{\circ} \mathrm{C}$ in a humidified $5 \% \mathrm{CO}_{2}-95 \%$ air incubator. At subconfluence, cells were recovered with versene (Gibco BRL) and cultured in Lab-Tek chamber slides (Nunc, VWR, Strasbourg, France) at $10^{4}$ cells per well for immunocytochemistry and Terminal transferase (TdT)-mediated dUTP nick-end labeling (TUNEL) analysis or in 96-well plates (Nunc) at $10^{4}$ cells per well for apoptosis detection by immunoenzymatic assays or in 6-well plates (Nunc) at $10^{5}$ cells per well for bromodeoxyuridine (BrdU, Sigma-Aldrich, Saint Quentin Fallavier, France) incorporation analysis.

Treatments of U-87 MG cells. Apoptotic studies were performed after a 48-h cell exposure to human recombinant FasL (rh Super FasLigand, Alexis Biochemicals, San Diego, CA), alone or associated with etoposide (Sigma-Aldrich). Apoptosis was evaluated by immunoenzymatic assay to determine the level of cytoplasmic soluble nucleosomes (Cell death detection enzyme-linked immunosorbent assay; Roche Diagnostic, Meylan, France) of glioma cells stimulated with increasing concentrations of etoposide $(5,10,20,40,60$ and $80 \mu \mathrm{g} / \mathrm{ml})$ or of FasL $(5,10,20,40,60$ and $80 \mathrm{ng} / \mathrm{ml})$ alone or associated with etoposide $(10 \mu \mathrm{g} / \mathrm{ml})$.

In addition, percentages of apoptotic cells were determined by TUNEL method on U-87 MG cells in medium alone (basal) or after exposure to FasL (40 ng/ml), etoposide $(10 \mu \mathrm{g} / \mathrm{ml})$ or etoposide $(10 \mu \mathrm{g} / \mathrm{ml})$ plus FasL $(40,60$ and $80 \mathrm{ng} / \mathrm{ml})$. Cell proliferation was determined by BrdU incorporation after FasL $(40 \mathrm{ng} / \mathrm{ml})$ or etoposide $(10 \mathrm{ng} / \mathrm{ml})$ alone or both for cell exposure.

Immunofluorescence assays. Cells $\left(10^{4}\right.$ cells/well) were cultured for $72 \mathrm{~h}$ in 8-well Lab-Tek plates and stimulated for $48 \mathrm{~h}$ with FasL $(40 \mathrm{ng} / \mathrm{ml})$ and etoposide $(10 \mu \mathrm{g} / \mathrm{ml})$. Cells were fixed in paraformaldehyde (Sigma-Aldrich) at $4 \%$ in phosphatebuffer saline (PBS) $\left(\mathrm{NaCl} 0.13 \mathrm{M}, \mathrm{Na}_{2} \mathrm{HPO}_{4} 5.1 \mathrm{mM}, \mathrm{KH}_{2} \mathrm{PO}_{4}\right.$ $1.54 \mathrm{mM}$ ) for $30 \mathrm{~min}$ at room temperature and permeabilized using alcohol/acetone (v/v) (Sigma-Aldrich) for $5 \mathrm{~min}$ at $4^{\circ} \mathrm{C}$. After a 2-h saturation with $10 \%$ goat serum (Sigma-Aldrich) in PBS, cells were incubated for 90 min either with a mouse anti-neurofilament monoclonal antibody (mAb) (anti-NF mAb, 2F11, 1/50; DakoCytomation, Trappes, France), a rabbit anti-glial fibrillary acidic protein Ab (anti-GFAP Ab, 1/50; DakoCytomation), a mouse anti-human CD68 mAb ( $\mathrm{k}_{\mathrm{i}}-\mathrm{M} 7$, 1/50; Berhing, Rueil-Malmaison, France), a mouse anti-human leukocyte antigen (HLA) I mAb (HLA-A, B, C, W6/32, 1/10, hybridoma culture supernatant), a mouse anti-Fas mAb (B-G27, 1/20; Diaclone, Besançon, France) or isotypic controls (irrelevant IgG1 and IgG2a (B-Z1 and B-Z2; Diaclone) and rabbit Ig (DakoCytomation) diluted in saturating solution. Primary Abs were revealed by $30-\mathrm{min}$ incubation with Alexa Fluor 594-conjugated goat anti-mouse or anti-rabbit Ig Ab (1/9,000; Molecular Probes, Leiden, Netherlands). Cells were fixed with glycerol gelatin (Sigma-Aldrich) and examined by confocal microscopy (Carl Zeiss S.A.S, LSM 510, Jena, Germany).

Western blot analysis. Cells, at basal state or after FasL $(40 \mathrm{ng} / \mathrm{ml})$ and etoposide $(10 \mu \mathrm{g} / \mathrm{ml})$ exposure during $48 \mathrm{~h}$, were washed with PBS and lysed in appropriate buffer [50 mM Tris, 1\% NP-40, 0.25\% deoxycholate sodium, $150 \mathrm{mM} \mathrm{NaCl}$, $1 \mathrm{mM}$ EGTA, (Sigma-Aldrich), and Protease inhibitor cocktail set III (Calbiochem, San Diego, CA)]. After centrifugation at $14,000 \mathrm{x} \mathrm{g}$ for $15 \mathrm{~min}$ at $4^{\circ} \mathrm{C}$, supernatants were collected. Protein concentrations were determined by the Bradford method (Bio-Rad, Hercules, CA) (21), and $25 \mu \mathrm{g}$ proteins were boiled for $5 \mathrm{~min}$ in Laemli buffer $(625 \mathrm{mM}$ Tris $\mathrm{HCl}$, pH 6.8, 10\% glycerol, 2\% SDS, $0.01 \%$ bromophenol blue and $5 \%$ ß-mercaptoethanol), separated by $12 \%$ sodium dodecyl sulfate-PAGE and transferred onto nitrocellulose sheets (HAHY $0.45 \mu \mathrm{M}$; Millipore, St. Quentin-Yvelines, France). After a 3-h saturation with 5\% non-fat dried milk in PBS, the sheets were incubated overnight at $4{ }^{\circ} \mathrm{C}$ with an anti-Fas rabbit anti-serum (1/300, C-20; Santa Cruz Biotechnology, CA, USA) or isotypic controls, rabbit irrelevant Ig (DakoCytomation), diluted in $1.5 \%$ bovine serum albumin (Jacques Boy Institute S.A., Reims, France) in PBS. After washes in PBS, the sheets were revealed, after 1-h incubation with an anti-rabbit Ig peroxidase-stained goat anti-serum (1/1,000, DakoCytomation), by the Covalight enhanced chemiluminescence procedure (AbCys, Paris, France).

Cell death assays. To determine the apoptotic effect of FasL and/or etoposide, we used two different procedures, the detection of cytoplasmic soluble nucleosomes [Cell death 
detection enzyme-linked immunosorbent assay (ELISA plus)] and terminal transferase (TdT)-mediated dUTP nick-end labeling assays (TUNEL).

Cells were seeded in 96-multi-well plates $\left(10^{4}\right.$ cells/well $)$ and maintained for 3 days in culture. After 48-h stimulation with different molecules, the rate of apoptosis was measured using cell death detection ELISA plus (Roche Diagnostic) according to the manufacturer's instructions. Absorbance values were measured at $405 \mathrm{~nm}$ with an ELISA reader (Packard Instruments, Meriden, USA). Apoptotic indexes (mean $\pm \mathrm{SE}$ of four independent experiments) were calculated in reference to the values obtained with basal cells (four experiments, fixed to 1).

Apoptotic cells were then counted using the TUNEL assay (Promega, Charbonnières, France). Cells (10 $/$ well) were cultured for $72 \mathrm{~h}$ in Lab-Tek plates. After 48-h stimulation, cells were fixed with $4 \%$ paraformaldehyde diluted in PBS for $30 \mathrm{~min}$, permeabilized with $0.1 \%$ Triton X-100 (SigmaAldrich) in PBS for $5 \mathrm{~min}$ at $4^{\circ} \mathrm{C}$ and stained by the TUNEL method with fluorescein isothiocyanate (FITC) staining as described by the manufacturer. The reaction was stopped by a 10-min wash in $2 \mathrm{X}$ saline sodium citrate (SSC) and cells were counterstained with Evans' blue (Sigma-Aldrich). Cells were counted by fluorescence microscopy (Carl Zeiss S.A.S) with a magnification x200 (a minimum of 500 cells from 3 fields were counted for each condition).

Determination of cell proliferation. Cells seeded in 6-well plates $\left(10^{5}\right.$ cells/well) were maintained for 3 days in culture and incubated for $48 \mathrm{~h}$ with $20 \mu \mathrm{M}$ BrdU in each tested condition. Then, cells were permeabilized with $0.1 \%$ Triton X-100 1\% sodium citrate (Sigma-Aldrich) in PBS for 2 min on ice and DNA was denatured with $2 \mathrm{M} \mathrm{HCl}$ (Sigma-Aldrich) for $1 \mathrm{~h}$. $\mathrm{HCl}$ was neutralised with boric acid $0.1 \mathrm{M}$ pH 8.2 (SigmaAldrich) for $10 \mathrm{~min}$. After washes in PBS, $2 \times 10^{5}$ cells were resuspended in $10 \%$ FCS in versene with a mouse anti-BrdU $\mathrm{mAb}$ (Sigma-Aldrich) diluted at $1 / 100$, on ice, for $30 \mathrm{~min}$. Primary Ab was detected with a goat anti-mouse Ig FITCconjugated antibody (DakoCytomation) diluted at 1/100 in $10 \%$ FCS in versene during $30 \mathrm{~min}$ on ice. Finally, cells were fixed in $10 \%$ FCS - 1\% paraformaldehyde in versene.

Relative fluorescence intensity was measured by fluorescence-activated cell sorter analysis (Epics XLMCL Coulter, HIALEAH, Floride, USA). Each analysis was performed on at least 20,000 cells and repeated thrice. Results were the mean of three independent experiments.

$U-87 M G$ xenografts. The procedure of the present study followed the rules edited by French National Ethics Committee. Animals were given free access to food and water and were kept in individual cages in a sterile atmosphere. One week after their arrival, female nude rats (2 months of age, $159 \pm 8.59 \mathrm{~g}$, Charles River Laboratories, L'Arbresle, France) were injected with midazolam $(0.5 \mathrm{mg} / 100 \mathrm{~g}$, intramuscular; Merck, $\mathrm{NJ}$, USA) and anesthetized with ketamine ${ }^{\circledR}(5 \mathrm{mg} / 100 \mathrm{~g}$, intraperitoneal; Virbac SA, Carros, France). Rat heads were fixed in a stereotaxic apparatus (David Kopf instruments, Tujunga, CA) and a midline incision was made to expose the bregma, the zero coordinates. Stereotaxic coordinates from the right caudate putamen were determined according to Paxinos and
Watson atlas relative to the bregma. A burr hole was drilled over the right skull [antero-posterior $(\mathrm{AP})=0.5 \mathrm{~mm}$, lateral (L) $=-2.7 \mathrm{~mm}$ from bregma] (22).

Before cell grafts in the caudate putamen, stereotaxic implantation was first adapted by intra-cerebral injection of $2 \mu 1$ of methylene blue (Sigma-Aldrich) in order to verify previous coordinates.

Cell viability after $1 \mathrm{~h}$ in CSF was determined using Trypanblue (Sigma-Aldrich). U-87 MG cells were recovered and $10^{6}$ cells, suspended in $4 \mu 1$ synthetic CSF $(147 \mathrm{mM} \mathrm{NaCl}$, $2.7 \mathrm{mM} \mathrm{KCl}, 1.2 \mathrm{mM} \mathrm{CaCl}_{2}, 0.85 \mathrm{mM} \mathrm{MgCl}_{2}$, SigmaAldrich), were injected 4.4 deep from the dura via Hamilton syringe lowered in the hole during $8 \mathrm{~min}$. The needle was maintained in position for 2 min then withdrawn in $2 \mathrm{~min}$. The holes were closed with bone wax (Horsley wax, B Braun Medical, Boulogne, France) and the skin was closed with a suture. Five animals received only CSF as healthy controls.

Osmotic pump implantation. Four groups of five rats were used: CSF injected rats, xenografted rats, and xenografted rats treated with FasL and etoposide or with FasL, etoposide and dexamethasone.

Fifteen days after xenografts, Alzet osmotic pumps (Alzet, Model 1002; flow rate $=0.25 \mu 1 / \mathrm{h}$ during 14 days, Charles River Laboratories) were filled in sterile conditions with CSF only (healthy controls) or CSF containing FasL (0.47 ng/h) and etoposide $(75 \mathrm{ng} / \mathrm{h})$ or CSF containing FasL, etoposide and dexamethasone $(0.66 \mathrm{ng} / \mathrm{h})$, according to the manufacturer's instructions. Five grafted animals received no treatment as untreated controls. Rats were anesthetized as previously described and pumps were implanted into a subcutaneous pocket between the scapulae. The outlet of the osmotic pump cannula $(4.5 \mathrm{~mm})$ was lowered using the stereotaxic apparatus into the hole where cells were injected. Cannula was fixed to the skull with anchor screws and dental cement (Pr scell glass-ionomer; Pierre Roland, Merignac, France). The skin was then closed with a suture. Fifteen days later, according to the ethical protocol, euthanasia was practiced on animals, the pumps were removed, checked and the brain frozen at $-80^{\circ} \mathrm{C}$ for further analysis. Grafted rats were euthanised 30 days after xenograft or earlier in cases of severe neurological impairment.

Clinical follow-up. Clinical examination was performed daily after the surgery. Symptoms of neurological disturbances, including apathy, anorexia, loss of weight, epistaxis, paresia, loss of balance, proprioceptive disturbances and leaning one's head on the side, were looked for. Euthanasia was performed prematurely when severe dysfunctions such as anorexia, apathy or paralysis were observed.

Immunohistochemistry. Brain cryosections (12- $\mu \mathrm{m}$, coronal sections) were performed with cryostat (Leica CM3050, RueilMalmaison, France) and standard coloured with hemateineosin-safran (HES) or hematoxylin (Sigma-Aldrich) or stained by immunohistofluorescence. Cryosections were air-dried and fixed in acetone at $-20^{\circ} \mathrm{C}$ for $10 \mathrm{~min}$. Samples were washed thrice in PBS, and saturated with $10 \%$ FCS in PBS for $1 \mathrm{~h}$. Sections were incubated with primary Ab against human NF protein $(2 \mathrm{~F} 11,1 / 20)$, human GFAP protein $(1 / 20)$, human CD68 protein $\left(\mathrm{k}_{\mathrm{i}}-\mathrm{M} 7,1 / 20\right)$, human HLA-I proteins 

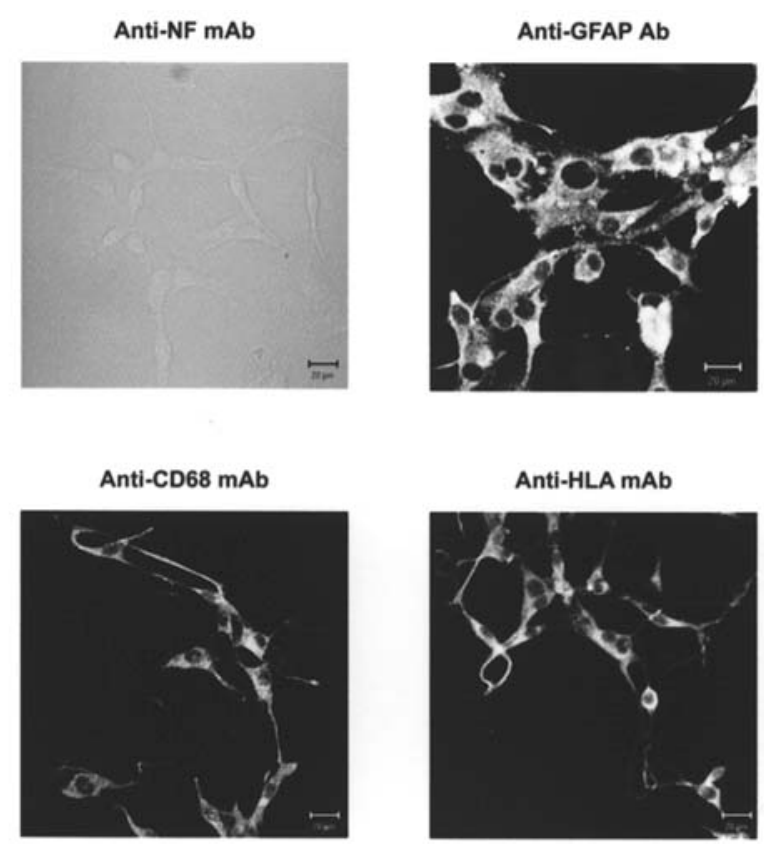

Figure 1. U-87 MG cells express GFAP, CD68 and HLA-I markers. Cells were stained with a monoclonal anti-neurofilament (anti-NF mAb), rabbit polyclonal anti-GFAP (anti-GFAP Ab), monoclonal anti-CD68 (anti-CD68 $\mathrm{mAb}$ ) and monoclonal anti-HLA-I (anti-HLA mAb) antibodies, revealed by goat anti-mouse or anti-rabbit Alexa Fluor 594-conjugated. Immunostaining was examined by confocal microscopy.

(W6/32, 1/20), human Fas protein (B-G27, 1/20) or IgG1 and IgG2a isotypic controls (B-Z1 and B-Z2) or rabbit irrelevant Ig for $2 \mathrm{~h}$ in $10 \%$ FCS in PBS. After washes in PBS, sections were incubated for $1 \mathrm{~h}$ with biotinylated rabbit anti-mouse $\mathrm{Ig}$, rat Ig absorbed (1/100, DakoCytomation) or Alexa Fluor 594-conjugated goat anti-rabbit Ig Ab $(1 / 9,000)$ diluted in $10 \%$ FCS in PBS. Biotinylated Ig treated sections were revealed with streptavidin red-phycoherythrin-cyanine 5 conjugated (DakoCytomation) diluted at 1/100 in PBS during 30 min. Cells were fixed with glycerol gelatin (Sigma-Aldrich) and examined by confocal microscopy.

Statistical analyses. Each assay was repeated at least thrice and results corresponded to mean \pm standard error. Statistical analyses (correlation test and ANOVA) relative to in vitro experiments were performed using Systat 7.0 (SPSS Inc., Evanston, IL).

Results dealing with tumour sizes were analysed using Tukey HSD multiple comparisons, as a post hoc ANOVA test, and General Linear Model, to infer the proper influence of each factor, implemented in Systat 7.0. In order to analyse etoposide's apoptotic effect compared to apoptotic basal level t-test was used.

\section{Results}

Characterization of U-87 MG cells. Cellular markers were used in order to characterize U-87 MG cells and to further identify them in rat brains after xenografts (Fig. 1). In vitro, U-87 MG cells did not express neurofilament, a neuronal marker (studied by anti-NF mAb), in contrast to the astrocytic marker stained by anti-GFAP $\mathrm{Ab}$ and to the microglial marker

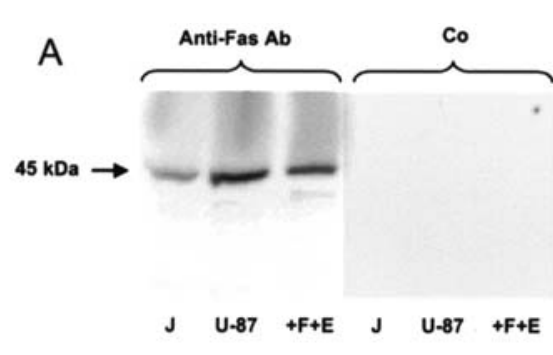

B

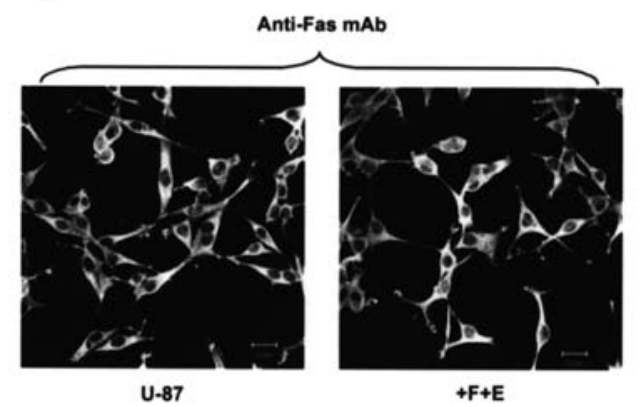

Figure 2. Fas is expressed at cell surface even after FasL and etoposide exposure. A, Fas proteins were first detected by Western blotting in Jurkat (J), as positive control, and in U-87 MG cells in basal conditions (U-87) or after FasL and etoposide $(+\mathrm{F}+\mathrm{E})$ exposure. Cells were lysed and proteins were separated by $12 \%$ sodium dodecyl sulfate-polyacrylamide gel electrophoresis, transferred onto nitrocellulose sheets, detected using a rabbit polyclonal anti-Fas anti-serum (anti-Fas $\mathrm{Ab}$ ) and revealed by chemiluminescence. Control for non-specific binding was performed using isotypic $\mathrm{Ab}(\mathrm{Co})$. B, Fas proteins were then detected by immunocytochemistry on U-87 MG cells at basal state (U-87) or after 48-h exposure to FasL and etoposide $(+\mathrm{F}+\mathrm{E})$. An anti-Fas mAb was used to detect Fas receptor, revealed by a goat antimouse Alexa Fluor 594-conjugated antibody and examined by confocal microscopy.

revealed by an anti-CD68 $\mathrm{mAb}$. In addition, the human specificity of glioblastoma cells was assessed by their expression of HLA-class I antigens (detected by anti-HLA mAb). No staining was observed with isotypic controls (data not shown).

U-87 MG cells expressed Fas receptor in basal conditions or after FasL and etoposide exposure. By Western blotting of the whole proteins extracted from U-87 MG cells (U-87) or U-87 MG cells treated with FasL and etoposide $(+\mathrm{F}+\mathrm{E})$, a single 45-kDa protein corresponding to Fas was detected with a polyclonal anti-Fas Ab. The T lymphocytic Jurkat cell line (J) was used as positive control (Fig. 2A). Immunocytochemical studies performed with an anti-Fas mAb on basal (U-87) or on FasL and etoposide-treated U-87 MG cells (+ F + E) showed homogenous staining of the cell membranes (Fig. 2B), confirming the results obtained by Western blotting. No staining was observed with isotypic controls, in Western blotting (Co) and immunocytochemical experiments (data not shown).

The combination of FasL and etoposide increased U-87 MG cell apoptosis and decreased cell proliferation in vitro. The apoptotic indexes of U-87 MG cells in the presence of increasing concentrations of etoposide $(5-80 \mu \mathrm{g} / \mathrm{ml})$ were first determined by cell death detection ELISA plus (Fig. 3A). 
A

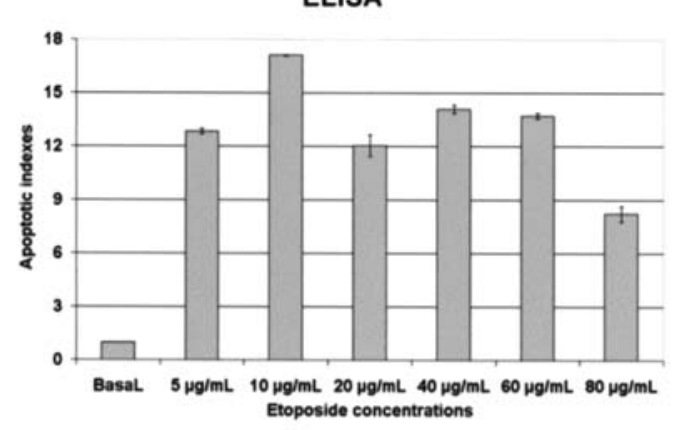

B

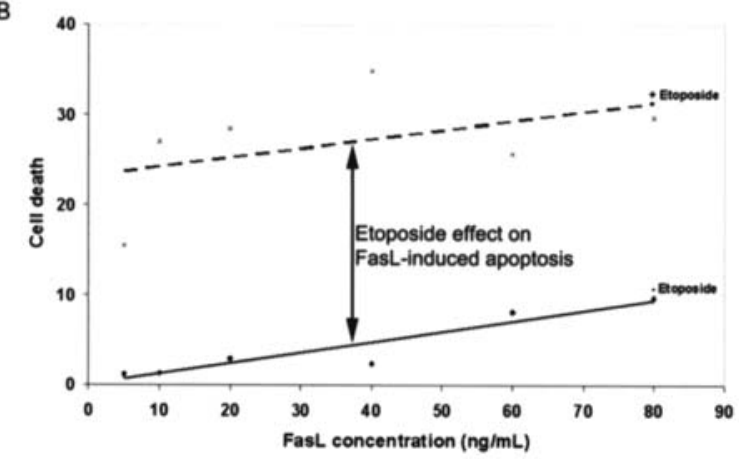

Figure 3. A significant increase of U-87 MG cell apoptosis is induced by a combination of FasL and etoposide. A, apoptotic levels of cells after etoposide $(5-80 \mu \mathrm{g} / \mathrm{ml})$ exposure during $48 \mathrm{~h}$ were determined by cell death detection ELISA plus method, demonstrating that $10 \mu \mathrm{g} / \mathrm{ml}$ of etoposide was enough to induce cell death. B, by testing increasing concentrations of FasL, it was determined that FasL-induced apoptosis is dose-dependant. Moreover, both molecules have a supra-additive effect on cell apoptosis compared to indexes obtained for FasL alone, whatever the concentration of FasL.

These indexes were significantly increased compared to basal cell death ( $\mathrm{t}$-test, $\mathrm{p}<0.013$ for all etoposide concentrations) with a maximal apoptotic rate obtained with $10 \mu \mathrm{g} / \mathrm{ml}$ of etoposide $(17.1 \pm 1.3)$. However, no significant variations of apoptotic indexes were recorded with any etoposide concentrations (ANOVA, $\mathrm{n}=24, \mathrm{p}>0.5$ ). Moreover, Pearson correlation analysis with mean values demonstrated that there is no correlation between apoptotic rates and etoposide concentration variations $(n=6, p>0.15)$. Considering these results, a $10 \mu \mathrm{g} / \mathrm{ml}$ of etoposide concentration was further employed in all experiments as this concentration is currently used in vitro $(14,23)$. Apoptotic rates were next measured with increasing concentrations of FasL (5-80 ng/ml, Fig. 3B). In contrast to the previous case, FasL apoptotic rates increased significantly in a dose-dependent manner (Pearson $\mathrm{r}=0.89$, $\mathrm{n}=6, \mathrm{p}=0.016)$. ANOVA test confirmed the significant effect of FasL ( $n=34, p<0.0001)$.

Finally, U-87 MG cells showed increasing apoptotic levels (Fig. 3B) when treated simultaneously with etoposide (10 $\mu \mathrm{g} /$ $\mathrm{ml})$ and increasing concentrations of FasL $(5-80 \mathrm{ng} / \mathrm{ml})$ (Pearson $\mathrm{r}=0.85, \mathrm{n}=6, \mathrm{p}=0.03$ ).

As no dose-dependent effect of etoposide on apoptotic indexes was found, we were unable to use the isobologram method (24) to assess the effect of FasL and etoposide combination. So, for each concentration of FasL, we compared the apoptotic level differences between FasL plus etoposide and FasL alone with apoptotic values observed with etoposide

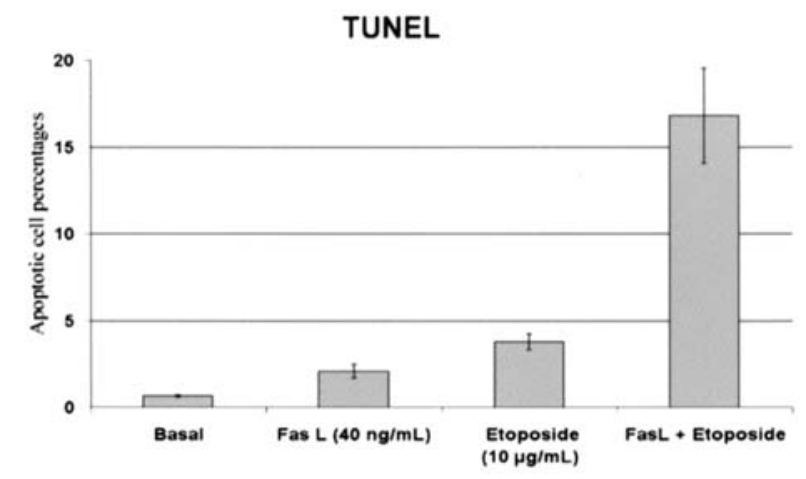

Figure 4. FasL and etoposide have a supra-additive effect on U-87 MG cell apoptosis. Apoptotic percentages of cells in the presence of FasL (40 ng/ml) or etoposide $(10 \mu \mathrm{g} / \mathrm{ml})$, independently or in association, were determined by TUNEL methods.

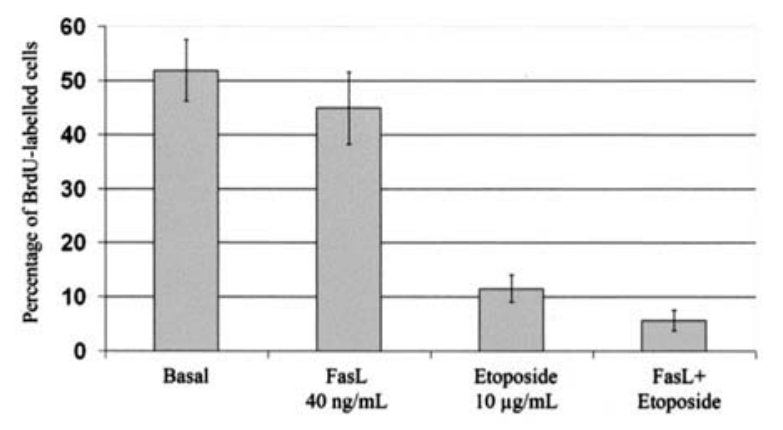

Figure 5. Cell proliferation is diminished by FasL and etoposide exposure. Cell division was detected by BrdU incorporation, revealed by anti-BrdU monoclonal antibody and goat anti-mouse Ig FITC-conjugated before flow cytometry analyses.

alone. The difference values $(27.1 \pm 5.5)$ were significantly higher than apoptotic levels recorded with etoposide alone (13.5 \pm 2.0 ) (ANOVA, $n=12, p=0.00846$ ), demonstrating that FasL and etoposide have a supra-additive effect.

Cell death percentages determined by TUNEL method confirmed the results obtained with ELISA cell death method (Fig. 4). Two-way ANOVA $(n=12)$ proved the significant effect of FasL at $40 \mathrm{ng} / \mathrm{ml}(\mathrm{p}<0.0001)$, of etoposide at $10 \mu \mathrm{g} /$ $\mathrm{ml}(\mathrm{p}<0.0001)$, and of the combination of both molecules $(\mathrm{p}=0.0006)$, illustrating again their supra-additive effect. Moreover, the percentage of cell apoptosis increased significantly with increasing FasL concentrations (between 40 and $80 \mathrm{ng} / \mathrm{ml}$ ) associated with etoposide $(10 \mu \mathrm{g} / \mathrm{ml})$ (Pearson $\mathrm{r}=0.95, \mathrm{n}=9$, $\mathrm{p}=0.0001$ ). Interestingly, $>50 \%$ of cells showed an apoptotic profile using FasL at $80 \mathrm{ng} / \mathrm{ml}$ associated with etoposide at $10 \mu \mathrm{g} / \mathrm{ml}$.

In addition, the anti-proliferative properties of these cell treatments were searched at $40 \mathrm{ng} / \mathrm{ml}$ of FasL and $10 \mu \mathrm{g} / \mathrm{ml}$ of etoposide (Fig. 5). Two-way ANOVA $(\mathrm{N}=15)$ showed that FasL alone had no significant effect $(\mathrm{p}=0.082)$ on $\mathrm{BrdU}$ incorporation, i.e. cell division, while etoposide greatly decreased cell mitosis $(\mathrm{p}<0.0001)$. The combination of FasL plus etoposide exhibited no significant anti-proliferative effect on U-87 MG cells ( $p>0.3$ ) in comparison to mitotic levels obtained when etoposide was tested alone. 
A

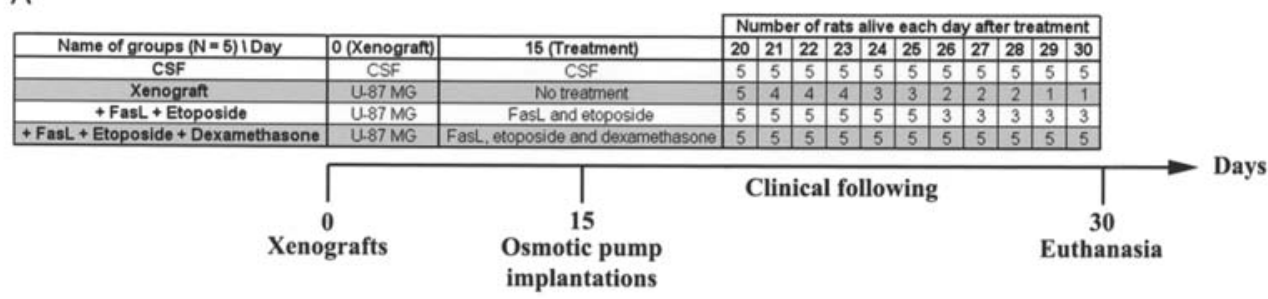

B

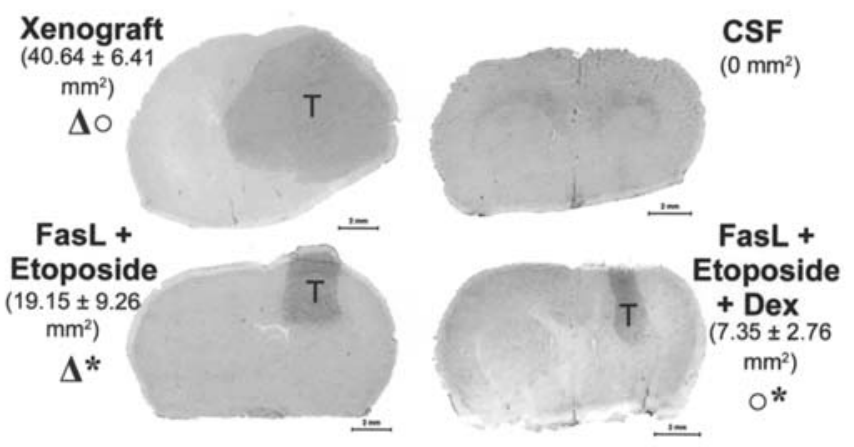

Figure 6. Fas, etoposide and dexamethasone association delayed xenografted rat symptom occurrence and reduced tumour development. A, different groups of rats ( $\mathrm{n}=5$ per group) were clinically followed-up in several conditions: rats xenografted without treatment (xenografts), rats xenografted and treated with FasL and etoposide (+ FasL + etoposide) or with FasL, etoposide and dexamethasone (+ FasL + etoposide + dexamethasone) or only injected with synthetic CSF as controls (CSF). Rats were euthanised at the occurrence of neurological involvement or at 30 days without symptoms. B, after xenografts and treatments, rat brains were frozen and cryosections were coloured with hematoxylin to detect tumour mass (T). Different conditions were analysed such as xenografted rats with U-87 MG cells (xenograft), injected rats with synthetic CSF (CSF), xenografted rats treated with FasL and etoposide (FasL + etoposide) and xenografted rats treated with FasL, etoposide and dexamethasone (FasL + etoposide + Dex). Statistical analyses were performed to determine tumour size variations between different treatment groups (a Tukey HSD Multiple comparisons test to compare xenografted rat tumour size, without treatment, with treated rat tumour size and a GLM to analyse dexamethasone's effect on tumour size between the two groups of treated rats). A decrease of tumour size was observed between xenografted (untreated rats) and FasL + etoposide treated rats $(\triangle)$ p $=0.014$; as for FasL + etoposide + dex $(0)$ p $=0.0008$. In addition a significant decrease of tumour size between the two treatments was observed when dexamethasone was added $\left(^{*}\right) \mathrm{p}=0.005$.

U-87 MG cell xenografts induced rat brain tumour. The theoretical stereotaxic coordinates $(\mathrm{Ap}=0.5 \mathrm{~mm}, \mathrm{~L}=-2.7 \mathrm{~mm}$ from bregma and dorso-ventral $=4.4 \mathrm{~mm}$ ) were tested and adapted to the surgical implements using methylene blue.

Before grafting, Trypan-blue tests assessed that the cell viability of cells maintained for $1 \mathrm{~h}$ in CSF (the delay between cells recovering and grafting) was not modified. Among the 5 nude rats that received U-87 MG cell graft in the brain, neurological symptoms appeared between the 20th day and the 30th day and this detection of symptoms was rapidly followed by euthanasia (Fig. 6A). Clinical examination, performed daily, showed general alteration such as apathy, loss of weight, epistaxis, loss of balance, proprioception disturbance, paralysis and leaning the head on the right side. After euthanasia, brain cryosections were coloured with hematoxylin (Fig. 6B). A large tumour $\left(40.64 \pm 6.41 \mathrm{~mm}^{2}\right.$, Fig. 6B) was detected by HES in the right caudate putamen (xenograft), in contrast to the control left one. Immunohistochemical staining showed that cell tumours $(\mathrm{T})$ expressed the same phenotype, GFAP ${ }^{+}$, $\mathrm{CD}^{6} 8^{+}$and $\mathrm{HLA}^{+}$, as in vitro cells while NF were only expressed by normal rat brain tissue (B) (Fig. 7). These data proved that tumours were truly developed from xenografts of human (HLA-expressing) glioma cells. Finally, Fas protein was still expressed in tumour cells, allowing further studies.

In healthy controls receiving only CSF injection, no neurological symptom (Fig. 6A) or lesion (Fig. 6B) was detectable on the 30th day before xenografts and animals gained $12.7 \%$ of their initial weight.
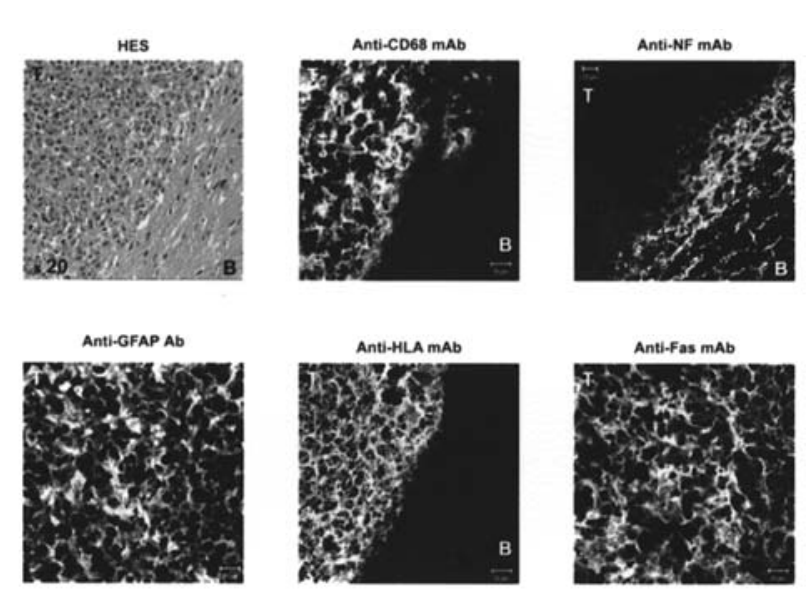

Figure 7. Immunohistological analyses reveal GFAP, CD68 and HLA-I marker expression of tumour cells. Rat brains were frozen, and sections were analysed by HES coloration or immunostaining. Cryosections were stained with a monoclonal anti-neurofilament (anti-NF mAb), a rabbit polyclonal anti-GFAP (anti-GFAP Ab), a monoclonal anti-CD68 (anti-CD68 $\mathrm{mAb}$ ) and a monoclonal anti-HLA-I (anti-HLA mAb) Ab. They were revealed by a goat anti-mouse biotin-conjugated antibody followed by streptavidin red-phycoherythrin-cyanine 5 or by a goat anti-rabbit Alexa Fluor 594-conjugated antibody. Immunostaining was examined by confocal microscopy. B, rat brain; $\mathrm{T}$, tumour.

Intracerebral delivery of FasL and etoposide decreased tumour invasion. FasL and etoposide treatments $(n=5)$ were performed 15 days after U-87 MG cell xenograft with a 
continuous and complete treatment during 15 days for three of them, whereas the osmotic pump failed to a continuous delivery of the FasL plus etoposide solution in two others. Indeed, these two treated rats developed neurological symptoms on the 26th day after the graft, similar to those observed in xenografted and untreated rats. After euthanasia, systematic examination of the osmotic pump showed that the reservoir remained full with drug solutions in both rats exhibiting neurological symptoms. Thus, neurological symptoms could be related to the growth of brain tumour due to a defective treatment (Fig. 6A). In contrast, 30 days after xenograft, the 3 other rats did not develop any neurological involvement and presented a weight increase of $15.9 \%$. Furthermore, after euthanasia at 30th day, no residual drugs were detected into the pump. Altogether, tumours that were detected in these 5 rats had a smaller size $\left(19.15 \pm 9.26 \mathrm{~mm}^{2}\right.$, Tukey's test, $\mathrm{p}=0.014$ ) than tumours obtained in untreated rats (Fig. 6B). Nevertheless, tumours expressed the same cellular markers as previously determined (data not shown) but macroscopic examination of sections showed additional inflammatory lesions in the area of tumour characterized by oedema and fibrous deposits that were detected in rats treated with FasL and etoposide.

Dexamethasone increased FasL and etoposide anti-tumour effect. In regards to these inflammatory lesions, dexamethasone, a glucocorticoid currently associated with chemotherapy, that decreases inflammatory reaction and oedemas due to tumour, was then added by osmotic pump. Thirty days after xenografts, none of the 5 rats treated with FasL, etoposide and dexamethasone developed any neurological symptom (Fig. 6A). However, they showed a loss of weight of $7.6 \%$. Brain cryosections and hematoxylin colorations (Fig. 6B) showed a significant smaller tumour compared to tumours of untreated rats $\left(7.35 \pm 2.76 \mathrm{~mm}^{2}\right.$ vs $40.64 \pm 6.41 \mathrm{~mm}^{2}$, Tukey's test, $\mathrm{p}=0.0008$ ) (Fig. 6B). Moreover, General Linear Model proved that dexamethasone has a significant effect $(\mathrm{p}=0.05)$ compared to FasL and etoposide treatment $(\mathrm{p}=0.0056)$ on tumour size. Cellular markers expressed by tumours were similar to those of untreated xenografted rats (data not shown). Interestingly, one rat tumour had completely regressed.

\section{Discussion}

Human malignant glioma cells are highly resistant to various apoptotic stimuli, such as irradiation and cytotoxic drugs, and currently used treatments failed to improve the survival of patients. Cellular studies have shown that the resistance of glioma to apoptosis could be related to alterations of apoptoticsignalling pathways (25). Such mechanisms were clearly identified in glioblastoma, where Fas receptor activation did not induce apoptosis but rather cell survival and proliferative response (7). However, it was demonstrated that the association of conventional chemotherapeutic drugs could sensitize glioblastoma cells to Fas-dependent apoptosis (26). Therefore, promising therapeutic research could be developed from the characterization of such combinations of drugs, able to induce Fas-apoptotic response in resistant glioma cells. The aim of the present report was to define the apoptotic and antiproliferative effects of FasL in combination with etoposide, a currently used chemotherapeutic drug by in vitro assays and to determine the anti-tumour activity of both molecules.

Fas expression was detected in cells maintained in vitro, as well as in tumours developed after xenografts in rat brain. This expression was not decreased after exposure to FasL and etoposide, allowing the use of these drugs to induce cell apoptosis. FasL $(27,28)$ and etoposide $(29)$ cytotoxicities were already studied separately on glioblastoma. In the present report, we demonstrated that the combination of both molecules exerted significant apoptotic and anti-proliferating effects on U-87 MG cells. Indeed, while FasL alone or etoposide alone slightly increased cell apoptosis, their association exerted a supra-additive effect in a FasL dose-dependent manner, potentiating their respective pro-apoptotic functions. Such sensitization of U-87 MG cells to Fas-induced apoptosis by etoposide could be related to its ability to induce apoptosis through a proteolytic processing of caspase-8 (15). Likewise, cell proliferation was very slightly decreased in the presence of FasL alone $(40 \mathrm{ng} / \mathrm{ml})$ but strikingly reduced in association with etoposide at $10 \mu \mathrm{g} / \mathrm{ml}$. This concentration of etoposide is currently used in vitro $(14,23)$.

Considering these results, the anti-tumour effect of both molecules was studied in vivo upon experimental glioblastoma in rats. This model was obtained after U-87 MG cell xenografts in brains of nude rats, inducing cell proliferation and tumour development (30) and was characterized by immunostaining. Tumour cells expressed the astrocytic maker, GFAP, as expected (31) and also a macrophage marker, CD68, as already described in human malignant astrocytes (32). In addition, HLA expression provides an appropriate control to assess that tumours were truly developed from U-87 MG cell graft and were not a reactive glial cell proliferation after rat brain implantation.

A treatment associating FasL and etoposide was evaluated, based on a continuous delivery of drugs into tumour, through the implantation of an osmotic pump on the 15th day after xenografts. We have detected that the combination of FasL and etoposide significantly reduced the size of tumours, even in animals with residual drugs in the reservoir, due to a defective pump. However, marked inflammatory lesions were detected mostly in the surrounding areas of tumours in animals treated with the combination of FasL and etoposide and not in untreated rats. These lesions could be related to the inflammatory activity of FasL through chemokines and IL-1 release (33-35).

Therefore, to overcome inflammation, a steroidal antiinflammatory agent, dexamethasone was added. Surprisingly, the combination of the three molecules strongly decreased cell tumour spreading, compared to those observed in rats treated with FasL and etoposide only.

The anti-proliferative mechanism of dexamethasone was determined as an inhibition of solid tumour angiogenesis (36). However, the anti-tumour effect of dexamethasone used alone is debated as exhibiting an anti-apoptotic effect (37) or increasing (38) or preventing (39) tumour cell proliferation. Thus, the anti-tumour effect of dexamethasone is yet to be elucidated. Nevertheless, the anti-tumour effect of dexamethasone associated with FasL and etoposide has already been demonstrated in vitro on B-cells (40). Indeed, in B lymphoma, Fas-triggering was inefficient in inducing apoptosis and B-cells 
were also resistant to etoposide treatment, but able to undergo apoptosis after dexamethasone addition (40).

Our results have shown an important decrease of tumour size related to the anti-tumoural effect of the simultaneous action of FasL, etoposide and dexamethasone. In terms of clinical perspectives, this combination seems to be promising as it decreased tumour development and morbidity in this experimental model. However, it needs to be further adapted in order to develop available human treatment.

\section{Acknowledgements}

This work was supported by grants from Conseil Régional du Limousin, Ligue Nationale Contre le Cancer (comités de la Corrèze et de la Haute-Vienne). We are very grateful to Professor Ramade and Olivier Decourt for their helpful contributions.

\section{References}

1. Weller M, Rieger J, Grimmel C, van Meir EG, De Tribolet N, Krajewski S, Reed JC, von Deimling A and Dichgans J: Predicting chemoresistance in human malignant glioma cells: the role of molecular genetic analyses. Int J Cancer 79: 640-644, 1998.

2. Yount GL, Haas-Kogan DA, Levine KS, Aldape KD and Israel MA: Ionizing radiation inhibits chemotherapy-induced apoptosis in cultured glioma cells: implications for combined modality therapy. Cancer Res 58: 3819-3825, 1998.

3. Ashkenazi A and Dixit VM: Death receptors: signaling and modulation. Science 281: 1305-1308, 1998.

4. Scaffidi C, Schmitz I, Zha J, Korsmeyer SJ, Krammer PH and Peter ME: Differential modulation of apoptosis sensitivity in CD95 type I and type II cells. J Biol Chem 274: 22532-22538, 1999.

5. Arai H, Gordon D, Nabel EG and Nabel GJ: Gene transfer of Fas ligand induces tumor regression in vivo. Proc Natl Acad Sci USA 94: 13862-13867, 1997.

6. Medema JP, De Jong J, van Hall T, Melief CJ and Offringa R: Immune escape of tumors in vivo by expression of cellular FLICE-inhibitory protein. J Exp Med 190: 1033-1038, 1999.

7. Shinohara H, Yagita H, Ikawa Y and Oyaizu N: Fas drives cell cycle progression in glioma cells via extracellular signal-regulated kinase activation. Cancer Res 60: 1766-1772, 2000.

8. De Vore R, Hainsworth J, Greco FA, Hande K and Johnson D: Chronic oral etoposide in the treatment of lung cancer. Semin Oncol 19: 28-35, 1992.

9. Belani CP, Doyle LA, and Aisner J: Etoposide: current status and future perspectives in the management of malignant neoplasms. Cancer Chemother Pharmacol 34: 118-126, 1994.

10. Wang JC, Caron PR and Kim RA: The role of DNA topoisomerases in recombination and genome stability: a doubleedged sword? Cell 62: 403-406, 1990.

11. Chen AY and Liu LF: DNA topoisomerases: essential enzymes and lethal targets. Annu Rev Pharmacol Toxicol 34: 191-218, 1994.

12. Shimada K, Nakamura M, Ishida E, Kishi M, Yonehara S and Konishi N: c-JunNH2-terminal kinase-dependent Fas activation contributes to etoposide-induced apoptosis in p53-mutated prostate cancer cells. Prostate 55: 265-280, 2003.

13. Kasibhatla S, Brunner T, Genestier L, Echeverri F, Mahboubi A and Green DR: DNA damaging agents induce expression of Fas ligand and subsequent apoptosis in T lymphocytes via the activation of NF-kappa B and AP-1. Mol Cell 1: 543-551, 1998.

14. Boesen-De Cock JG, De Vries E, Williams GT and Borst J: The anti-cancer drug etoposide can induce caspase- 8 processing and apoptosis in the absence of CD95 receptor-ligand interaction. Apoptosis 3: 17-25, 1998.

15. Boesen-De Cock JG, Tepper AD, De Vries E, van Blitterswijk WJ and Borst $\mathrm{J}$ : Common regulation of apoptosis signaling induced by CD95 and the DNA-damaging stimuli etoposide and gammaradiation downstream from caspase-8 activation. J Biol Chem 274: 14255-14261, 1999.

16. Wesselborg S, Engels IH, Rossmann E, Los M and SchulzeOsthoff K: Anticancer drugs induce caspase-8/FLICE activation and apoptosis in the absence of CD95 receptor/ligand interaction. Blood 93: 3053-3063, 1999.
17. Kiya K, Uozumi T, Ogasawara H, Sugiyama K, Hotta T, Mikami T and Kurisu K: Penetration of etoposide into human malignant brain tumors after intravenous and oral administration. Cancer Chemother Pharmacol 29: 339-342, 1992.

18. MacDonald TJ, Arenson EB, Ater J, Sposto R, Bevan HE, Bruner J, Deutsch M, Kurczynski E, Luerssen T, McGuireCullen P, O'Brien R, Shah N, Steinbok P, Strain J, Thomson J, Holmes E, Vezina G, Yates A, Phillips P and Packer R: Phase II study of high-dose chemotherapy before radiation in children with newly diagnosed high-grade astrocytoma: final analysis of Children's Cancer Group Study 9933. Cancer 104: 2862-2871, 2005.

19. Slave I, Schuller E, Falger J, Gunes M, Pillwein K, Czech T, Dietrich W, Rossler K, Dieckmann K, Prayer D and Hainfellner J: Feasibility of long-term intraventricular therapy with mafosfamide $(n=26)$ and etoposide $(n=11)$ : experience in 26 children with disseminated malignant brain tumors. J Neurooncol 64: 239-247, 2003.

20. Wang H, Li M, Rinehart JJ and Zhang R: Pretreatment with dexamethasone increases antitumor activity of carboplatin and gemcitabine in mice bearing human cancer xenografts: in vivo activity, pharmacokinetics, and clinical implications for cancer chemotherapy. Clin Cancer Res 10: 1633-1644, 2004.

21. Bradford M: A rapid and sensitive method for the quantitation of microgram quantities of protein utilizing the principle of protein-dye binding. Anal Biochem 72: 248-254, 1976.

22. Paxinos G and Watson C: The Rat Brain in Stereotaxic Coordinate. Academic Press Inc. Ltd., London, 1982.

23. Takahashi M, Mukai H, Toshimori M, Miyamoto M and Ono Y: Proteolytic activation of PKN by caspase- 3 or related protease during apoptosis. Proc Natl Acad Sci USA 95: 11566-11571, 1998.

24. Zhao L, Wientjes MG and Au JL: Evaluation of combination chemotherapy: integration of non-linear regression, curve shift, isobologram, and combination index analyses. Clin Cancer Res 10: 7994-8004, 2004

25. Roth W and Weller M: Chemotherapy and immunotherapy of malignant glioma: molecular mechanisms and clinical perspectives. Cell Mol Life Sci 56: 481-506, 1999.

26. Xia S, Rosen EM and Laterra J: Sensitization of glioma cells to Fas-dependent apoptosis by chemotherapy-induced oxidative stress. Cancer Res 65: 5248-5255, 2005.

27. Frankel B, Longo SL, Leach C, Canute GW and Ryken TC: Apoptosis and survival in high-grade astrocytomas as related to tumor Fas (APO-1/CD95) expression. J Neurooncol 59: 27-34, 2002.

28. Robe PA, Nguyen-Khac M, Jolois O, Rogister B, Merville MP and Bours V: Dexamethasone inhibits the HSV-tk/ganciclovir bystander effect in malignant glioma cells. BMC Cancer 5: 32, 2005.

29. Lavicka J, Sarissky M, Mirossay A, Sulla I, Mojzis J and Mirossay L: Diazepam enhances etoposide-induced cytotoxicity in U-87 MG human glioma cell line. Fund Clin Pharmacol 15: 201-207, 2001

30. Ozawa T, Wang J, Hu LJ, Bollen AW, Lamborn KR and Deen DF: Growth of human glioblastomas as xenografts in the brains of athymic rats. In Vivo 16: 55-60, 2002.

31. Ito $M$, Nagashima $T$ and Hoshino $T$ : Quantitation and distribution analysis of glial fibrillary acidic protein in human glioma cells in culture. J Neuropathol Exp Neurol 48: 560-567, 1989.

32. Leenstra S, Das PK, Troost D, De Boer OJ and Bosch DA: Human malignant astrocytes express macrophage phenotype. J Neuroimmunol 56: 17-25, 1995.

33. Wajant H, Pfizenmaier K and Scheurich P: Non-apoptotic Fas signaling. Cytokine Growth Factor Rev 14: 53-66, 2003.

34. Imamura R, Konaka K, Matsumoto N, Hasegawa M, Fukui M, Mukaida N, Kinoshita T and Suda T: Fas ligand induces cellautonomous NF-kappaB activation and interleukin-8 production by a mechanism distinct from that of tumor necrosis factor-alpha. J Biol Chem 279: 46415-46423, 2004.

35. Regardsoe EL, McMenamin MM, Charlton HM and Wood MJ: Local adenoviral expression of Fas ligand upregulates proinflammatory immune responses in the CNS. Gene Ther 11: 1462-1474, 2004.

36. Wolff JE, Molenkamp G, Hotfilder M and Laterra J: Dexamethasone inhibits glioma-induced formation of capillary like structures in vitro and angiogenesis in vivo. Klin Padiatr 209: 275-277, 1997. 
37. Nzang Nguema G, Boghossian S, Dardevet D, Grizard J and Alliot J: Effect of treatment with dexamethasone on protein intake in adult and old Lou/c/jall rats. Mech Ageing Dev 126: 655-663, 2005.

38. Zibera C, Gibelli N, Butti G, Pedrazzoli P, Carbone M, Magrassi L and Robustelli della Cuna G: Proliferative effect of dexamethasone on a human glioblastoma cell line (HU 197) is mediated by glucocorticoid receptors. Anticancer Res 12: 1571-1574, 1992.
39. Kaup B, Schindler I, Knupfer H, Schlenzka A, Preiss R and Knupfer MM: Time-dependent inhibition of glioblastoma cell proliferation by dexamethasone. J Neurooncol 51: 105-110, 2001.

40. Roue G, Lancry L, Duquesne F, Salaun V, Troussard X and Sola B: Upstream mediators of the Fas apoptotic transduction pathway are defective in B-chronic lymphocytic leukemia. Leuk Res 25: 967-980, 2001. 